\title{
Synthesis of a paraffin phase change material microencapsulated in a siloxane polymer
}

\author{
Witold Fortuniak • Stanislaw Slomkowski • \\ Julian Chojnowski • Jan Kurjata • Adam Tracz • \\ Urszula Mizerska
}

Received: 18 April 2012 /Revised: 20 June 2012 / Accepted: 18 August 2012 / Published online: 7 September 2012

(C) The Author(s) 2012. This article is published with open access at Springerlink.com

\begin{abstract}
The coemulsification method suitable for the formulation of microcapsules of $n$-eicosane coated with a polysiloxane is developed. This method allows to synthesize coreshell microcapsules of paraffin which have the shape of spheres or distorted spheres and are designed for the use as phase change materials. The microcapsules are formed in aqueous phase by the precipitation of $n$-eicosane together with modified polyhydromethylsiloxane from a common solvent which is miscible with aqueous media. The polysiloxane is modified by the attachment of silylvinyl and alkoxy functions before coemulsification with the paraffin. It also contains the $\operatorname{Pt}(0)$ Karstedt catalyst. The microcapsules formed by coemulsification are stabilized by the in situ cross-linking of the polysiloxane shell. The shell is additionally modified by the in situ generation of silanol groups which provide colloidal stabilization of microspheres in aqueous phase. Microcapsules were studied by DSC, SEM, optical polarized microscope, and by thermooptical analysis (TOA).
\end{abstract}

Keywords PCM microcapsules · Microencapsulation ·

Microencapsulated phase change materials .

Polyhydromethylsiloxane $\cdot$ Microcapsules $\cdot$ Karstedt catalyst

\section{Introduction}

There has been a growing interest in phase change materials (PCM), which are converted from solid to liquid and from

W. Fortuniak $\cdot$ S. Slomkowski $\cdot$ J. Chojnowski $(\bowtie) \cdot$ J. Kurjata

A. Tracz $\cdot$ U. Mizerska

Center of Molecular and Macromolecular Studies,

Polish Academy of Sciences,

Sienkiewicza 112,

90-363 Łódź, Poland

e-mail: jchojnow@cbmm.lodz.pl liquid to solid phase with a large heat effect. They are commonly used for thermoregulation, thermal energy storage, and cooling. Among many other applications they are used by textile industry for the thermoregulation of clothing [1-5]. In clothes, the PCM, which has a suitably matched phase change temperature, is soothing the effect of outside thermal peaks by the absorption and release of thermal energy. It gives the human body a feeling of thermal comfort and protects people working in adverse temperature conditions against thermal shocks. Paraffins, linear chain saturated hydrocarbons, with the melting and crystallization temperatures quite similar to the temperature of the human body (e.g., eicosane), are often used as PCM [6-8]. Importantly, they have a high latent heat of fusion which gives them high heat capacities. Their fusion temperature depends on the hydrocarbon chain length, so it may be easily adjusted to the needed temperature range. Moreover, paraffins are chemically and thermally stable and physiologically neutral.

Although PCMs are used in various forms, such as bulk materials, sheets, and particles dispersed in matrices, the most convenient form of their use in textile industry is core-shell microcapsules [9, 10]. Microcapsules can be easily dispersed in materials or attached to their surfaces. The rate of heat exchange with an encapsulated PCM is high due to its large surface to volume ratio. Moreover, microcapsules do not change the outer appearance of clothing and its characteristics, such as softness, breathability, and color. Melamine [11-15] or urea [16-18] resins cross-linked by formaldehyde are frequently used as the encapsulating material. Since there is a tendency to eliminate carcinogenic formaldehyde from the manufacturing of products used in contact with human body, our attention was turned to polysiloxanes as candidates for encapsulants for PCMs. These polymers are attractive because they are physiologically neutral, chemically and thermally stable, and are resistant to oxygen, water, and water vapor. They are sufficiently 
mechanically strong and elastic to withstand the volume change and deformation of PCMs during the phase change. The thermomechanical damage of the PCM microcapsule shell due to its rigidity may be a problem [18], and in some cases, soft segments are introduced into encapsulating polymer with purpose to prevent the shell breakage $[19,20]$.

Polysiloxane particles have been used as drug carriers for drug-controlled release [21, 22], carriers of metal catalysts [23, 24], dyes [25], and magnetic nanoparticles [26]. These particles are often named capsules but they do not have core-shell structure. They have form of microsphers in which other materials are dispersed. This type of particles does not fit for PCMs as the dispersion decreases paraffin thermal capacity. Organotrialkoxysilanes were used for the formation of polysilsesquioxane coating on particles by a sol-gel interfacial process [27, 28]. These coatings are rigid and may be cut or broken by sharp edges of crystals formed in the phase change process. Miniemulsion technique was recently used to encapsulate some materials with polysiloxanes. This method leads to the nano-sized core-shell particles $[29,30]$, which are not suitable for PCMs.

The encapsulation of a paraffin particle with polysiloxane to form a core-shell micron-sized structure is not an easy problem. Most of the encapsulation procedures are performed in aqueous systems. Polysiloxane monomers are soluble in paraffins and insoluble in water which makes the encapsulation of paraffin particles by an emulsion polymerization difficult. Coating of paraffin particles with a hydrophobic polysiloxane is also hindered because this polymer has a tendency to form a separate microphase in aqueous systems. Our attempts to use a polysiloxane with hydrophilic tetraalkylammonium chloride groups pendant to the polymer chain were unsuccessful as well. Unexpectedly we found that stable microcapsules with $n$-eicosane core and polysiloxane shell may be obtained when a modified polyhydromethylsiloxane is subjected to coemulsification with the paraffin in an aqueous system, with the in situ crosslinking of the encapsulant and with simultaneous additional modification of the formed particle shell. Our method is based on particular activity of the Karstedt catalyst (platinum $\operatorname{Pt}(0)$ complex with 1,3-divinyl-1,1,3,3-tetramethyldisiloxane) which may simultaneously act as the catalyst of four reactions involved in the encapsulation process, i.e., hydrosilylation [31], alcoholysis of hydrosilane [32], hydrolysis of $\mathrm{SiH}$ and $\mathrm{SiH}$ condensation with $\mathrm{SiOH}$ [33].

\section{Experimental}

\section{Materials}

Polyhydromethylsiloxane (PHMS) with trimethylsiloxane end groups was a product of ABCR Gmbh under name HMS 991 having viscosity $15-25 \mathrm{cSt}$ corresponding to $\mathrm{Mn}=1.5 \times 10^{3}$ to $2.0 \times 10^{3} \mathrm{~g} / \mathrm{mol} ; 1,3$-divinyltetramethyldisiloxane (DVTMDS) with declared purity $97 \%$ was provided also by $\mathrm{ABCR}$ poly[vinyl alcohol] (PVA) with declared purity $99.5 \%$ and Mn $7.2 \times 10^{4} \mathrm{~g} / \mathrm{mol}$ was purchased from Polskie Odczynniki Chemiczne (POCH); isopropanol with declared purity $99.5 \%$ was also obtained from POCH; tetrahydrofurane from CHEMPUR was p.a. grade dioxane with declared purity $99.8 \%$ was purchased from CHEMPUR; $n$-eicosane with declared purity $99 \%$ was from Alfa Aesar Gmbh. All these chemicals were used without additional purification; however, their purity was confirmed by the gas chromatography analysis. Platinum complex $20 \mathrm{wt} \% \mathrm{Pt}(0)$ was kindly offered by Momentive Performance Materials Leverkusen.

\section{Physical methods}

Thermal characteristics: differential scanning calorimeter (DSC) thermograms were registered with a DSC 2920 Temperature Modulated TA Instrument at the rate of temperature change $5 \mathrm{~K} / \mathrm{min}$ and using ca. 5-mg samples. Thermogravimetric measurements were performed using a HIRES TGA 2950 Thermogravimetric Analyzer TA Instruments. Thermooptical studies were performed using a METTLER TOLEDO FP82HT HOT stage with control processor FP90.

Solid state ${ }^{29} \mathrm{Si}$ NMR spectra were registered with a DSX 400 Bruker spectrometer. The spectra were acquired with cross-polarization, at $59.627 \mathrm{MHz}$ applying $90-\mu$ s pulses, 6 -s pulse delay, and 3-ms contact time, with samples in $4.0-\mathrm{mm}$ zirconia rotors spinning at $8 \mathrm{kHz}$. The peak positions were referenced to the signal of $\mathrm{Q}_{8} \mathrm{M}_{8}$.

SEM images were taken with a JEOL JSH $5500 \mathrm{LV}$ in high-vacuum mode at the accelerated voltage of $10 \mathrm{kV}$. Samples were coated with a fine gold layer, about $20 \mathrm{~nm}$ thick using ion coating JEOL JFC 1200 apparatus. Optical microscopy observations of microcapsules were done using microscope optical with polarizer Nicon Eclips E400 POL.

Generation of microcapsules with $n$-eicosane core

The solution of $16.5 \mathrm{~g}$ of PHMS with $3.1 \mathrm{~g}$ of DVTMDS in $25 \mathrm{~mL}$ of tetrahydrofurane (THF) was heated to $45{ }^{\circ} \mathrm{C}$ and $0.025 \mathrm{~g}$ of a $\operatorname{Pt}(0)$ catalyst solution was introduced. An increase of viscosity of the solution was observed. The solution was stirred for $20 \mathrm{~min}$ at $45^{\circ} \mathrm{C}$ and then introduced to a reactor in which the solution of $n$-eicosane $40 \mathrm{~g}$ in $110 \mathrm{~mL}$ of isopropanol was stirred at $45^{\circ} \mathrm{C}$. The resulting solution was stirred for additional $5 \mathrm{~min}$ and thermostated at $45{ }^{\circ} \mathrm{C}$. Then the solution was quickly introduced to the $150 \mathrm{~mL}$ of water thermostated at $45{ }^{\circ} \mathrm{C}$ containing the $0.55 \mathrm{~g}$ of dissolved PVA. The mixture was homogenized for $25 \mathrm{~s}$ using a high-speed MPW-120 homogenizer set to $4,000 \mathrm{rpm}$. The formed emulsion was introduced to a $5-\mathrm{L}$ 
Fig. 1 Scheme of the generation of paraffin microcapsules encapsulated in polysiloxane by coemulsification method

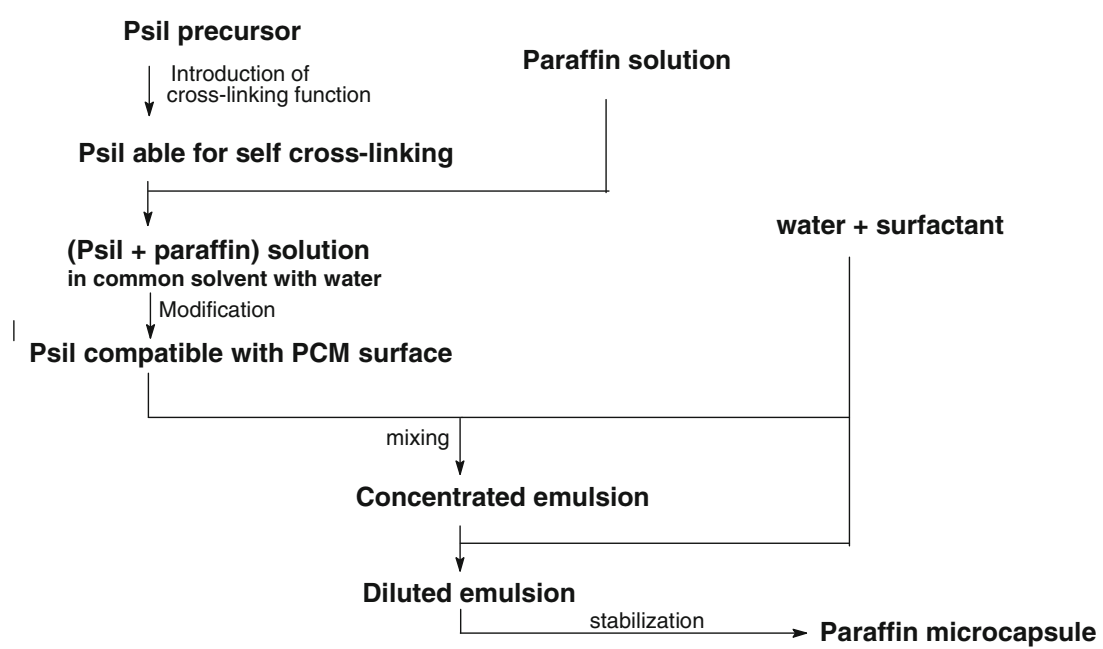

reactor equipped with an anchor stirrer in which $1.85 \mathrm{~L}$ of the aqueous solution of the $6.55 \mathrm{~g}$ of PVA was stirred at $45^{\circ} \mathrm{C}$. Stirring was continued for $70 \mathrm{~h}$ after which microcapsules were separated by centrifugation. The isolated microcapsules were carefully washed with water to remove surfactant from their surfaces. Their shape did resemble distorted spheres and the yield of microcapsules with the linear size in the range between 2 and $12 \mu \mathrm{m}$ was $70 \%$. Temperatures of fusion and crystallization were 37.4 and $30.1{ }^{\circ} \mathrm{C}$ respectively. The heat of fusion was $159 \mathrm{~J} / \mathrm{g}$.

\section{Results and discussion}

Preparation of microcapsules

The general scheme of the synthesis of the paraffin corepolysiloxane shell microcapsules is shown in Fig. 1. The precursor of the encapsulating material is PHMS of molecular weight about $2,000 \mathrm{~g} / \mathrm{mol}$. This polymer is modified to gain the ability for selfcross-linking. For this purpose, it is subjected to hydrosilylation of DVTMDS cross-linker. The reaction, catalyzed by platinum $\mathrm{Pt}(0)$ complex (Karstedt catalyst), in its first stage proceeds according to Eq. 1, leading to PHMS with vinyl pendant groups bonded to polysiloxane chain by an ethylenedisiloxane bridge, Eq. 1 .
The attachment of DVTMDS to the polysiloxane chain in the first step is necessary to prevent the penetration of this compound into the paraffin phase during the coemulsification and stabilization steps. However, the pendant vinyl groups may undergo subsequent hydrosilylation, which finally would results in the polymer cross-linking. This hydrosilylation is not desirable in the initial step, so at a suitable moment the reaction is slowed down by the dilution of the system with isopropanol solution of paraffin to give the time to perform further operations needed to form the polysiloxane coating on paraffin core before the cross-linking occurs.

In order to determine the moment at which the first step of the hydrosilylation process should be terminated, this reaction was parallelly monitored by the tracking of the variation of the viscosity of the reacting mixture. In the initial stage, when reaction 1 dominates, the viscosity increases slowly. The consecutive hydrosilylation of the second vinyl group is accompanied with a more rapid increase in the viscosity, which approaches infinity at gel point. At the half time of the hydrosilylation reaction needed to achieve gel point, i.e., well before the viscosity rapidly increases, the reacting mixture is added to solution containing the paraffin dissolved in a significant amount of isopropanol or in a mixture of isopropanol with dioxane or THF.

Then the hydrosilylation is effectively slowed down by the alcohol and by the dilution effect. The $\operatorname{Pt}(0)$

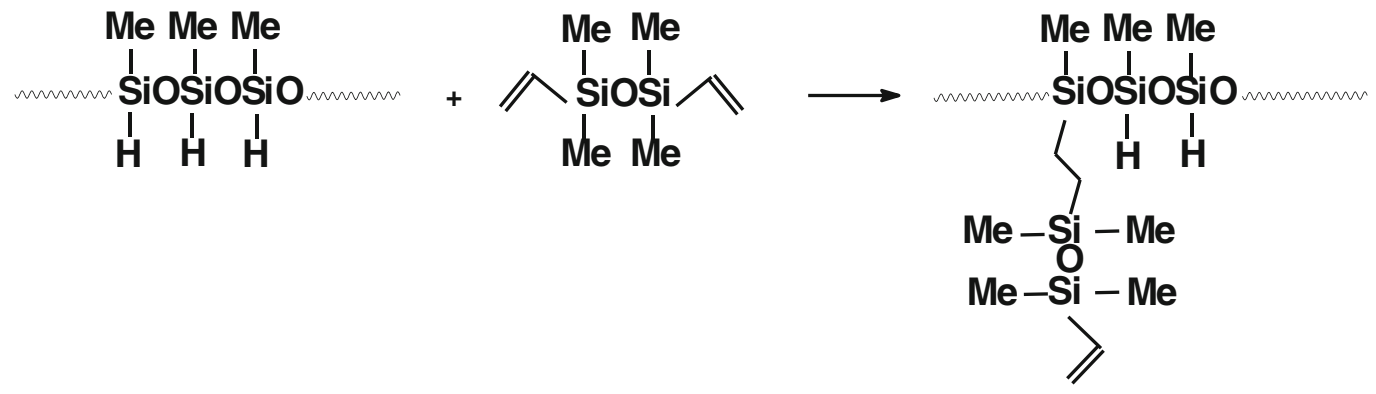


catalyst present in the reaction mixture promotes also the substitution of isopropoxy groups to the polymer chain, Eq. 2. Separate studies of this reaction revealed that several percent of $\mathrm{SiH}$ is transformed to $\mathrm{SiO} i \mathrm{Pr}$ in this stage of the process. These isopropoxy groups improve the compatibility of the polysiloxane with the paraffin surface thus making easier the formation of the coating on paraffin particles. The using of isopropanol or its mixture with dioxane or THF is important as they dissolve well the polysiloxane-paraffin-catalyst mixture and at the same time they are miscible with water.
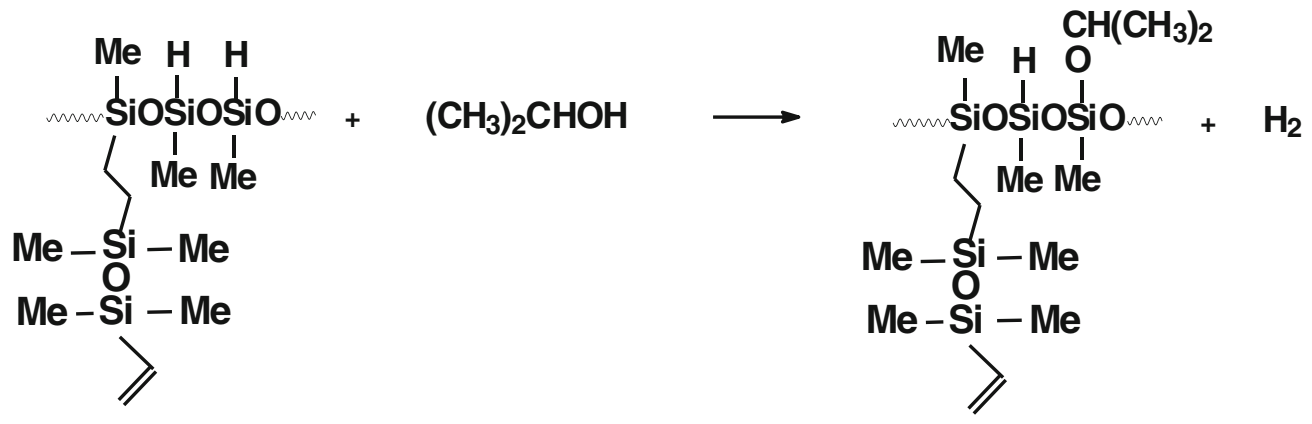

The concentrated solution of the modified PHMS with paraffin is thermostated at a temperature above the paraffin melting point and is mixed, with a limited amount of aqueous solution of PVA used here as a surfactant. This operation is performed using a highspeed homogenizer, at a temperature above the melting point of paraffin. An emulsion of microdroplets of liquid paraffin embedded in polysiloxane is formed. The emulsion is unstable as the microcapsules are not fully formed and the encapsulant has not yet been crosslinked. The further physical and chemical processes are carried out after dilution of the emulsion by the PVA in water solution, having the same PVA concentration and the same temperature as the water used in the emulsification process.

The diluted emulsion is stirred for up to $70 \mathrm{~h}$ at a temperature higher than the paraffin melting point. A series of important chemical reactions occurs during this procedure, but it is worth noting that they must be preceded by the formation of the polysiloxane coating on paraffin microdroplets which takes place shortly after the dilution of emulsion. The chemical reactions which follow this physical process are shown in Eqs. 3-5. All of them are promoted by $\mathrm{Pt}(0)$ complex present in the polysiloxane shell.

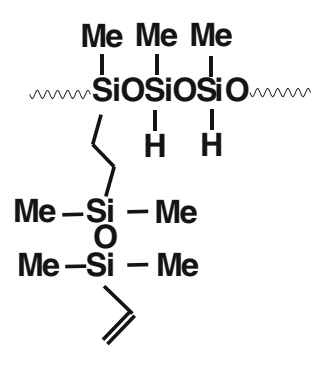

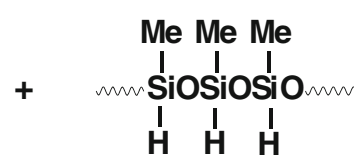
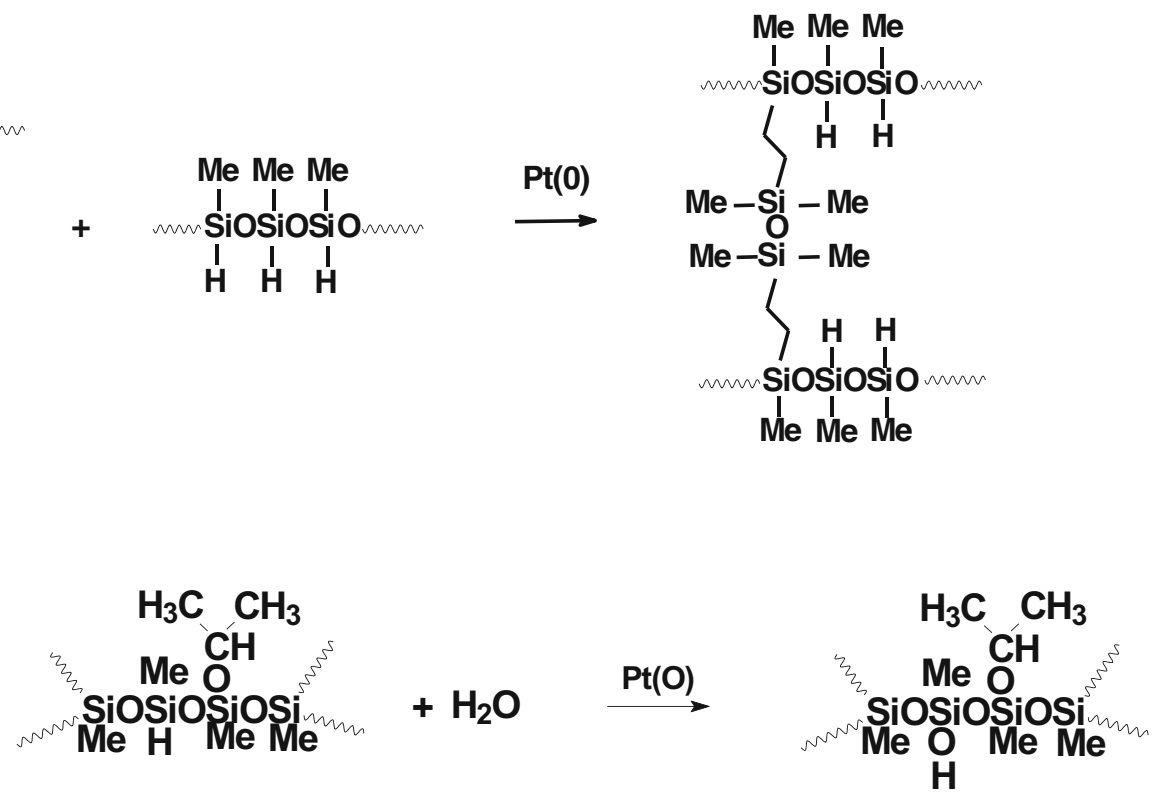


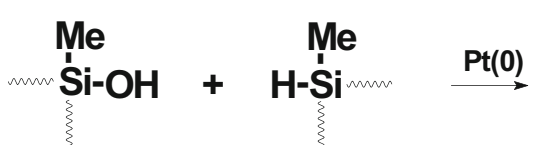

The cross-linking of the modified PHMS takes place in result of hydrosilylation of the vinyl group pendant to polysiloxane chain with $\mathrm{SiH}$ groups in another polymer chain. Thus, dialkyl disiloxane bridges are formed between polysiloxane chains, Eq. 3 . The reaction is catalyzed by the $\operatorname{Pt}(0)$ complex which was introduced to PHMS in the initial hydrosilylation stage. This catalyst promotes also the hydrolytic cleavage of $\mathrm{Si}-\mathrm{H}$ which leads to the generation of silanol groups on the polysiloxane chains, Eq. 4. These hydroxyl functions are very important because they make the microcapsules hydrophilic enhancing their dispersibility in aqueous systems. These groups are also useful for binding the microcapsules to a textile material surface. The silanol groups in the dehydrocondensation reaction with the $\mathrm{SiH}$ groups in polysiloxane catalyzed by the $\operatorname{Pt}(0)$ complex form siloxane bridges, Eq. 5. This reaction significantly contributes to the polysiloxane cross-linking and therefore makes shells of microcapsules stronger. Formally, the same bridges could be also formed in result of the homocondensation of silanol groups; however, this condensation does not proceed in the absence of any acidic, basic, or ionic substances, which are required for the catalysis of this reaction. All reactions $3-5$ are promoted by $\operatorname{Pt}(0)$ complex located in the polysiloxanes shell, but the activity of the catalyst in this system is relatively low. Consequently, these reactions occur slowly which is advantageous because it provides enough time to shape shells of microcapsules before the encapsulant is cross-linked. The reactions which occur during the micropcapsule stabilization were monitored by ${ }^{29} \mathrm{Si}$ MAS NMR. The NMR spectrum of the final product is shown in Fig. 2.

It should be mentioned that the Karstedt catalyst has been used so far mostly for the catalysis of hydrosilylation [31]. Its application for the catalysis of other reactions is very seldom, see references $[32,33]$. In the process described here, the $\operatorname{Pt}(0)$ complex, besides hydrosilylation, catalyzes also three other above-mentioned reactions. All of them are very important for the successful synthesis of the microcapsule shells.

The isolation of microcapsules may be performed by sedimentation under gravitational forces or facilitated by centrifugation or by filtration. The density of the microcapsules is close to the density of water, which makes difficult their isolation by sedimentation. The presence of a submicron fraction of microparticles may pose a problem during the filtration. The microcapsules, after their isolation from the aqueous system, are subjected to freeze-drying.

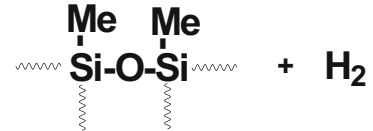

The yield of microcapsules was about $70 \%$. The optimal weight content of the polysiloxane coating was $33 \%$.

\section{Characterization of microcapsules}

${ }^{29} \mathrm{Si}$ MAS NMR spectra were analyzed with the purpose to obtain information on the chemical structure of the microcapsule shells. A spectrum of $n$-eicosan-containing microcapsules is shown in Fig. 2. The dominating peak at $-57 \mathrm{ppm}$ is that of silicon in the polymer chain bearing the hydroxyl group. A small signal at $-59 \mathrm{ppm}$ of silicon atom with bound izopropoxyl group is superimposed on the right wing of the silanol signal. The silicon in the polymer chain linking it to another chain by carbosiloxane and by siloxane bridges give resonances at -21 and $-66 \mathrm{ppm}$, respectively. Rather, a small number of the unreacted $\mathrm{SiH}$ groups remains in the polymer giving signal at $-37 \mathrm{ppm}$. The polysiloxane shells contain a great number of silanol groups which are present in the polymer bulk. The most important are those which are located on the shell surface because they make surface of microcapsules hydrophilic, which helps to redisperse them in aqueous systems after removal of surfactant.

Thermal behavior of microcapsules was studied by differential scanning calorimetry (DSC), and by thermooptical analysis. An example of the DSC thermograms corresponding to heating from the crystalline state and cooling from the molten $n$-eicosane in microcapsules is shown in Fig. 3 . The

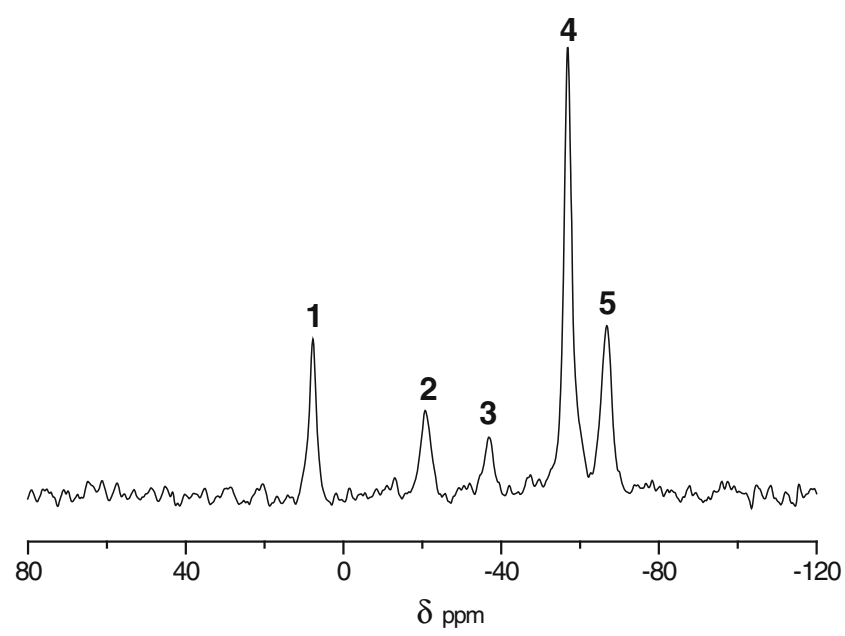

Fig. $2{ }^{29} \mathrm{Si}$ MAS NMR spectrum of $n$-eicosane microcapsules encapsulated in polysiloxanes: $1-\left(\mathrm{CH}_{2}\right) \mathrm{Me}_{2} \mathrm{SiOSi}+\mathrm{Me}_{3} \mathrm{SiOSi} ; 2-$ $\left(\mathrm{CH}_{2}\right) \mathrm{MeSi}(\mathrm{OSi})_{2} ; 3-(\mathrm{H}) \mathrm{MeSi}(\mathrm{OSi})_{2} ; 4-(\mathrm{HO}) \mathrm{MeSi}(\mathrm{OSi})_{2}+$ $(\mathrm{PrO}) \mathrm{MeSi}(\mathrm{OSi})_{2} ; 5-\mathrm{MeSi}(\mathrm{OSi})_{3}$ 
endothermal peak of the PCM melting is of regular shape showing onset at $35{ }^{\circ} \mathrm{C}$ and maximum at $39{ }^{\circ} \mathrm{C}$, which is somewhat above the melting temperature of pure $n$-eicosane, $36.2{ }^{\circ} \mathrm{C}$. The difference results from the delay due to the rate of the temperature rise $5 \mathrm{~K} / \mathrm{min}$. At this rate, the phase change takes place within the range 35 to $43^{\circ} \mathrm{C}$ The endothermal heat effect is $160 \mathrm{~J} / \mathrm{g}$ which agrees well with the latent heat of melting of pure $n$-eicosane, $240 \mathrm{~J} / \mathrm{g}$, assuming that the $33 \mathrm{wt} \%$ of the microcapsule weight is occupied by polysiloxane shell. This conforms fairly well to the weight ratio of the polysiloxanes to paraffin used in the reaction. It should be mentioned that the DSC traces are not changed after 50 cycles of fusing and crystallization, which gives a proof of the thermal stability of the microcapsules.

The exothermal peak of crystallization of $n$-eicosane is splitted to two and ranges from 34 to $25^{\circ} \mathrm{C}$ with maxima at 31 and $30{ }^{\circ} \mathrm{C}$. The splitting comes from the polymorphism of $n$-eicosane [34].

Thermogravimetric studies showed that the onset of the $n$-eicosane microcapsule thermal decomposition is $156{ }^{\circ} \mathrm{C}$. At this temperature, cracking of the silicone coating of microsphere begins and the maximum of this process is observed at $213{ }^{\circ} \mathrm{C}$. Finally, almost all core is lost by evaporation at about $240{ }^{\circ} \mathrm{C}$. Polysiloxane shell undergoes restructurization as the sample temperature is increased and relatively large amount of residue is generated (about $33 \mathrm{wt} \%$ at $900{ }^{\circ} \mathrm{C}$ ). A high content of the residue is due to a high degree of cross-linking of the polysiloxane, which prevents its depolymerization and makes easier its transformation into the SiCO ceramics.

A microphotograph of $n$-eicosane microcapsules taken by an optical microscope with sample illuminated with polarized light and observation with cross-polarization is shown on Fig. 4. Isotropic shells of microcapsules built of

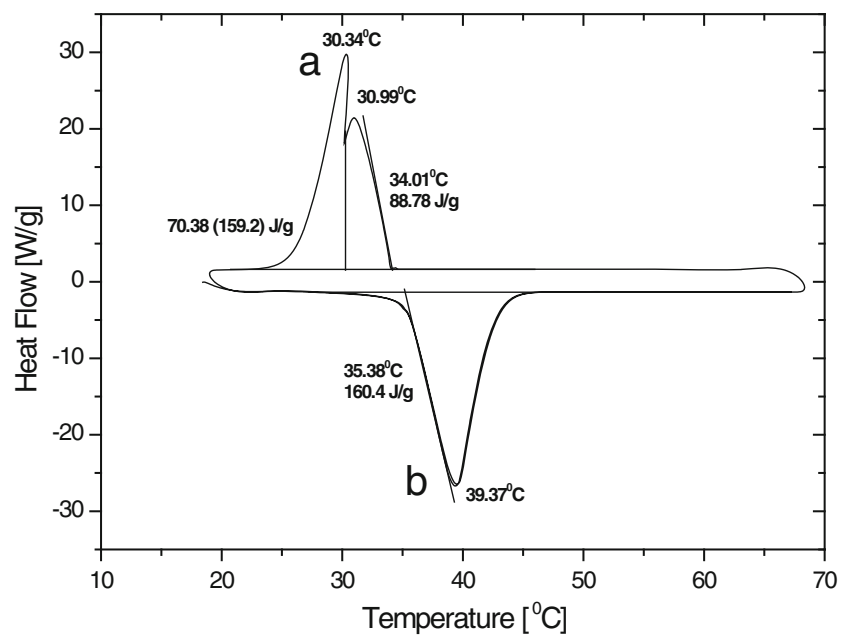

Fig. 3 DSC thermograms of microcapsules of $n$-eicosane encapsulated in polysiloxane. $a$ Cooling from melt, $b$ Heating from crystals

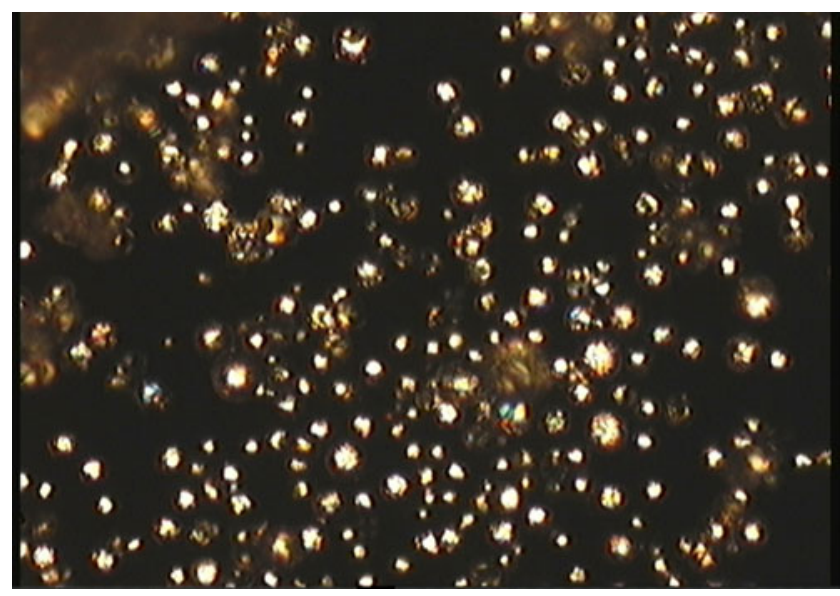

Fig. 4 Photogram of microcapsules of n-eicosane coated with polysiloxane taken by optical microscope with the illumination of sample by polarized light and observation with cross-polarization
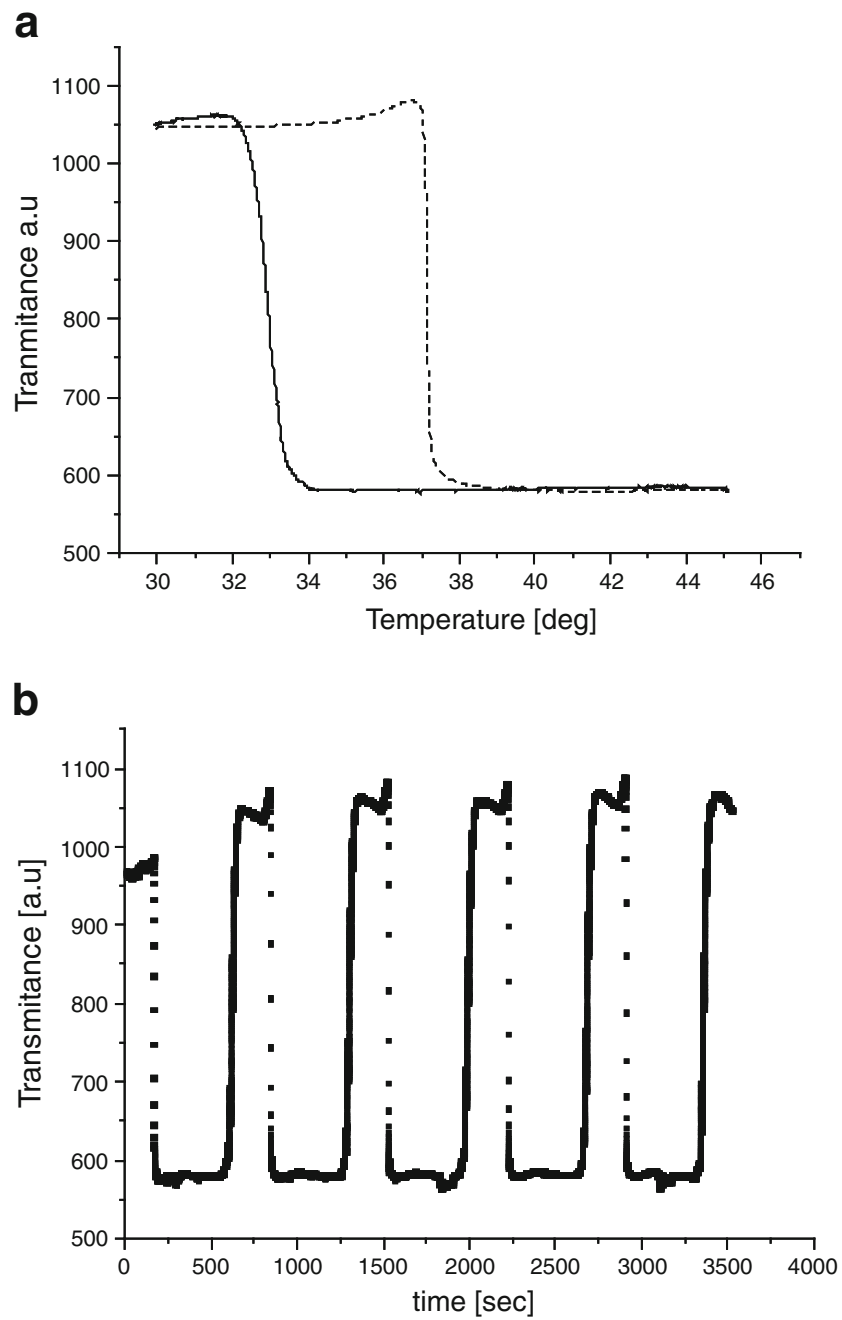

Fig. 5 Thermal behavior of n-eicosane encapsulated in polysiloxane studied by thermooptical method (TOA): a continuous line - crystallization from melt, dashed line - melting from crystals; $\mathbf{b}$ Several cycles of cooling from melt and heating from crystals 
Fig. 6 SEM images of microcapsules with n-eicosane core and polysiloxane shell obtained using conditions of synthesis and characteristics which are mentioned in Table 1: $\mathbf{a}$ - exp. I, $\mathbf{b}-\exp$. II, $\mathbf{c}-$ exp. III, $\mathbf{d}-\exp$ IV
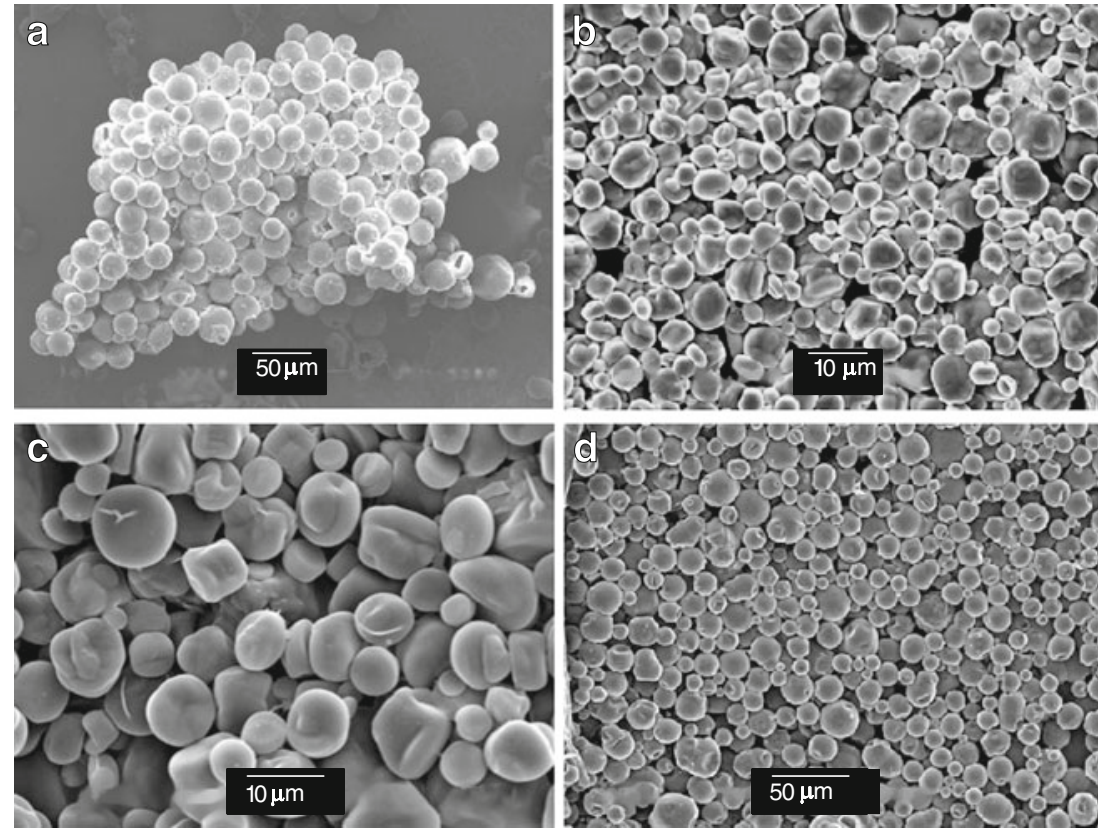

polysiloxane are not visible on this photogram, but birefringent crystalline paraffin cores are visible. The microscope image of the microcapsules on a graphite surface does not change after many cycles of heating above the paraffin melting point and cooling to crystals. This confirms the thermal stability of the microcapsules. Any leakage would lead to the spreading out of the liquid paraffin over the surface due to the well-known ability of paraffins to interact with graphite surface forming monolayers [35].

A thermooptical method of studies of the thermal behavior of microcapsules is worked out. A sample of microcapsules is placed between two crossed polarizers. In the temperature range above the melting point of paraffin, both phases, i.e., the polysiloxane chain and the paraffin core, are isotropic, so very little light is allowed to go through this system and the transmittance is at a low level as shown in Fig. 5a. When microcapsules are subjected to cooling from the paraffin melt the paraffin crystallization begins. The crystallization is accompanied with light scattering that results in an apparent increase of the transmittance. On heating from the crystal state, the transmittance abruptly falls down thus indicating the paraffin melting. The temperatures of fusion and crystallization of PCM may be readily determined from the transmittance traces, Fig. 5a. They agree well with the corresponding temperatures of melting and crystallization found by DSC, when both experiments are performed with the same heating and cooling rate. The thermooptical method may be used for the study of the behavior of microcapsules in multiple cycles of heating from crystal to liquid state and cooling from liquid to

Table 1 Synthesis of paraffin encapsulated in polysiloxane

\begin{tabular}{|c|c|c|c|c|c|c|c|c|c|}
\hline Number & PCM (quantity) g & Solvent & $\begin{array}{l}\text { PCM/ } \\
\text { solvent, } \\
\mathrm{g} / \mathrm{mL}\end{array}$ & $\begin{array}{l}\text { Catalyst Pt/capsule }{ }^{\mathrm{a}} \text {, } \\
\mathrm{mol} / \mathrm{g}\end{array}$ & $\begin{array}{l}\text { Time of } \\
\text { cross-linker } \\
\text { addition, } \\
\text { min }\end{array}$ & $\begin{array}{l}\text { Heat of } \\
\text { melt, } \mathrm{J} / \mathrm{g}\end{array}$ & $\begin{array}{l}\text { Melt. temp. } \\
\text { (range), }{ }^{\circ} \mathrm{C}\end{array}$ & $\begin{array}{l}\text { Cryst. temp. } \\
\text { (range), }{ }^{\circ} \mathrm{C}\end{array}$ & $\begin{array}{l}\text { Mean size } \\
\text { of capsule, } \\
\mu \mathrm{m}\end{array}$ \\
\hline I & $n$-eicosane (11) & Isoprop. & 0.37 & $9.7 \times 10^{-7}$ & 4 & 139 & $37.4(35-42)$ & $30(35-23)$ & 22.9 \\
\hline II & $n$-eicosane $(20)$ & Isoprop. & 0.33 & $7.8 \times 10^{-7}$ & 10 & 158 & $37.4(35-42)$ & $30(34-22)$ & 6.3 \\
\hline III & $n$-eicosane (40) & Isoprop.+THF 5:1 v/v & 0.30 & $4.3 \times 10^{-7}$ & 20 & 159 & $39.1(35-42)$ & $30(34-22)$ & 5.9 \\
\hline IV & $n$-eicosane (240) & Isoprop.+dioxane $1: 1 \mathrm{v} / \mathrm{v}$ & 0.55 & $3.2 \times 10^{-7}$ & 10 & 160 & $39.4(35-43)$ & $31(34-25)$ & 10.1 \\
\hline
\end{tabular}

Parameters were: polysiloxanes to paraffin $w / w$ ratio 0.5 , cross-linker (DVTMDS) to precursor polymer (PHMS) $w / w$ ratio 0.19 , mixing (homogenization in water): time $0.5 \mathrm{~min}$., temperature $45^{\circ} \mathrm{C}$, water to capsule ratio $2.5 \mathrm{~mL} / \mathrm{g}$, surfactant (PVA) concentration in water $3.6 \mathrm{~g} / \mathrm{L}$, stabilization: water to capsule milliliters per gram ratio $30-35 \mathrm{~mL} / \mathrm{g}$, time $30-70 \mathrm{~h}$, temp. $45-60^{\circ} \mathrm{C}$. PVA concentration is the same as in the mixing operation

${ }^{\mathrm{a}} \mathrm{PHMS}+\mathrm{DVTMDS}+n$-eicosane 
crystal. Figure $5 \mathrm{~b}$ shows traces of transmittance intensity changes for several cooling and heating cycles. These traces do not change their shapes, which can be considered as another proof of the thermal stability of the microcapsules.

Microcapsules are studied also by scanning electron microscopy (SEM). Examples of SEM images of encapsulated $n$-eicosane are shown in Fig. 6. Microcapsules have spherical or distorted spherical shapes. Their mean sizes estimated from the SEM images are shown in Table 1. They ranged from 5 to $22 \mu \mathrm{m}$. The average size and shape of the microcapsules depend on conditions of their formation. Some parameters of syntheses and characteristics of microcapsules obtained in various experiments are given in Table 1. A very important parameter is the time of the initial hydrosilylation step, i.e., time in which the DVTMDS cross-linker should be added to the PHMS chain. If this time period is too long, the vinyl group pendant to the polysiloxane chain enters hydrosilylation that results in a branching of PHMS and in an increase in molar mass of the polymer. As a result, the viscosity of PHMS is high when it precipitates in aqueous phase. The process described above leads to a distortion of microcapsules from their spherical shape as it is shown in Fig. 6bc. However, these distorted microcapsules, although not spherical, may have good thermal properties and may be stable, as it is shown in Figs. 3 and 5b. On the other hand, the time of the initial hydrosilylation cannot be too short, because an unreacted DVTMDS may penetrate into paraffin and deteriorate thermal properties of the microcapsules. The time of the initial hydrosilylation depends on the catalyst activity, which is sensitive to contaminations of used chemicals. This time was chosen as the half time of the hydrosilylation needed to achieve gel point and it was determined in a separate experiment for each synthesis.

\section{Conclusions}

The coemulsification in aqueous phase of $n$-eicosane with polyhydromethylsiloxane having pendant vinyl groups may lead to the formation of core-shell microparticles in which the paraffin is embedded in a polysiloxane shell. These particles are in situ stabilized by the polysiloxane cross-linking using the hydrosilylation process catalyzed by $\mathrm{Pt}(0)$ complex (Karstedt catalyst). This catalyst promotes also the competitive formation of silanol groups on the polysiloxane and their partial condensation with the $\mathrm{SiH}$ groups which additionally crosslinks the polysiloxanes shell.

The coemulsification is carried out in the temperature above the paraffin melting point using isopropanol or its mixture with THF or dioxane as common solvents for the paraffin-polysiloxane-catalyst system, which are miscible with water. These core-shell particles may serve as PCM microcapsules. They have a good thermal characteristic and withstand 50 fusion-crystallization cycles test.

Acknowledgments The research was performed in the frame of project NANOMITEX POIG 01.03.01-00-004-08 "Functional nano and micro textile materials" sponsored by European Union supervised by Institute of Textile Industrie in Łódź, Poland. Authors are grateful to Jos Delis $\mathrm{PhD}$ from Momentive Performance Materials Leverkusen for the generous gift of the concentrated solution of the $\operatorname{Pt}(0)$ complex catalyst.

Open Access This article is distributed under the terms of the Creative Commons Attribution License which permits any use, distribution, and reproduction in any medium, provided the original author(s) and the source are credited.

\section{References}

1. Zhang X (2001) Heat storage and thermoregulated textiles and clothing. In: Tao X (ed) Smart fibers and clothing. Woodhead Publishing, Cambridge, pp 34-57

2. Mondal S (2008) Phase change materials for smart textiles -an overwiew. Appl Therm Eng 28:1536-1550

3. Tang SLP, Stylios GK (2006) An overview of smart technologies for clothing and engineering. Int J Cloth Sci Techn 18:108-128

4. Zhao CY, Zhang GH (2011) Review on microencapsulated phase change materials (MEPCMs): fabrication, characterization and application. Renew Sust Energ Rev 15:3813-3832

5. Delgado M, Lazaro A, Mazo J, Zalba B (2012) Review on phase change material emulsions and microencapsulated phase change material slurries, materials, heat transfer studies and applications. Renew Sust Energ Rev 16:253-273

6. Hawlader MNA, Uddin MS, Khin MM (2003) Microencapsulated PCM thermal-energy storage system. Appl Energy 74:195-202

7. Onder E, Sarier N, Cimen E (2008) Encapsulation of phase change materials by complex coacervation to improve thermal performances of woven fabrics. Thermochim Acta 467:63-72

8. Chang CC, Tsai YL, Chiu JJ, Chen H (2009) Preparation of phase change materials microcapsules by using PMMA network-silica hybrid as the shell via sol-gel process. J Appl Polym Sci 112:1850-1857

9. Sanchez L, Lacasa E, Carmona M, Rodriguez JF, Sanchez P (2008) Applying and experimental design to improve the characteristics of microcapsules containing phase change materials for fabric uses. Ind Eng Chem Res 47:9783-9790

10. Zhou JW, Yu DM, Zhao YH, Su JF, Yuan XY (2011) Organic alkane phase change materials and their microencapsulation. Prog Chem 23:695-703

11. Shin Y, Yoo DI, Son K (2005) Development of thermoregulating textile materials with microencapsulated phase change materials (PCM). II. Preparation and application of PCM microcapsules. J Appl Polym Sci 95:2005-2010

12. Salaün F, Devaux E, Bourbigot S, Rumeau P, Chapuis PO, Saha SK, Volz S (2008) Polymer nanoparticles to decrease thermal conductivity of phase change materials. Thermochim Acta 477:25-31

13. Yu F, Chen ZH, Zeng XR (2009) Preparation, characterization, and thermal properties of microPCM containing $n$-dodecanol by using different types of styrene-maleic anhydride as emulsifier. Colloid Polym Sci 287:549-560

14. Gong CY, Zhang HZ, Wang XD (2009) Effect of shell materials on microstructure and properties of microencapsulated $n$-octadecane. Iranian Polym J 18:501-512 
15. Fan YF, Zhang XX, Wang XC, Li J, Zhy QB (2004) Super-cooling prevention of microencapsulated phase change material. Thermochim Acta 413:1

16. Sarier N, Onder E (2007) The manufacture of microencapsulated phase change materials suitable for the design of thermally enhanced fabrics. Thermochim Acta 452:149-160

17. Jin ZG, Wang YD, Liu JG, Yang ZZ (2008) Synthesis and properties of paraffin capsules as phase change materials. Polymer 49:2903-2910

18. Zhang XX, Tao XM, Yick KL, Wang XC (2004) Structure and thermal stability of microencapsulated phase-change materials. Colloid Polym Sci 282:330

19. Cho JS, Kwon A, Cho CG (2002) Microencapsulation of octadecane as a phase-change material by interfacial polymerization in an emulsion system. Colloid Polym Sci 280:260

20. Zhang H, Wang X (2009) Synthesis and properties of microencapsulated $n$-octadecane with polyurea shells containing different soft segments for heat energy storage and thermal regulation. Solar Energy Mater Solar Cells 93:1366

21. Carelli V, Coltelli S, Di Colo G, Nannipieri E, Serafini MF (1999) Silicone microspheres for $\mathrm{pH}$-controlled gastrointestinal drug delivery. Intern J Pharm 179:73-83

22. Gonzales B, Colilla M, Vallet-Regi M (2008) Time-delay release of bioencapsulates: a novel controlled delivery concept for bone implant technologies. Chem Mater 20:4826-4834

23. Motoyama Y, Mitsui K, Ishida T, Nagashima H (2005) Selfencapsulation of homogeneous catalyst species into a gel leading to a facile and efficient separation system of amine products in the $\mathrm{Ru}$-catalysed reduction of carboxamides with polymethylhydrosiloxane (PHMS). J Am Chem Soc 127:13150-13151

24. Chen HJ, Liu HW, Liao WS, Pan HB, Wai CM, Chiu KH, Jen JF (2012) Highly active and reusable palladium nanoparticle catalyst stabilized by polydimethylsiloxanes for hydrogenation of aromatic compounds in supercritical carbon dioxide. Appl Catal B-Environ 111:402-408
25. Zaggout FR (2006) Encapsulation of bromothymol blue pHindicator into a sol-gel matrix. J Disper Sci Technol 27:175-178

26. Bomberg I, Chang EP, Hatton TA, Concheiro A, Magarinos B, Alvarez-Lorenzo C (2011) Bactericidal core-shell paramagnetic nanoparticles functionalized with poly(hexamethylene biguanidine). Langmuir 27:420-429

27. Matsumoto T, Takayama Y, Wada N, Onoda H, Kojima K, Yamada H, Wakabayashi H (2003) Acid-free synthesis of poly-organosiloxane spherical particles using a W/O emulsion. J Mater Chem 13:1764-1770

28. Lu X, Xin Z (2007) Synthesis of poly(styrene-co-3-trimethoxysilyl propyl methacrylate) microspheres coated with polysiloxane layer. Colloid Polym Sci 285:599-604

29. Landfester K, Weiss CK (2010) Modern techniques for nano- and microreactors/-reactions. Adv Polym Sci 229:1-49

30. Bouanani R, Bendedouch D, Hemery P, Bounaceur B (2007) Encapsulation of montmorillonite in nanoparticles by miniemulsion polymerization. Colloids Surf A- Physicochem Eng Aspects 317:751-755

31. Marciniec B, Maciejewski H, Pietraszuk C, Pawluć P (2009) Hydrosilylation of alkenes and their derivatives. In: Marciniec B (vol ed) Hydrosilylation - a comprehensive review on recent advances. In: Matisons J (ser ed) Advances in silicon science, vol 1 Springer, Heidelberg, pp 3-44

32. Safa KD, Oskoei YM (2010) Functionalisation of the upper rim of calyx[4]arene via alcoholysis and hydrosilylation reactions. J Organomet Chem 695:505-511

33. Kurian P, Kennedy JP, Kisluik A, Sokolov A (2001) Poly(pentamethylcyclopentasiloxane). I. Synthesis and characterization. J Polym Sci Part A Polym Chem 40:1285-1292

34. Genovese A, Amarasinghe G, Glewis M, Mainwaring D, Shanks RA (2006) Crystallization, melting, recrystallization and polymorphism of n-eicosane for application as a phase change material. Thermochim Acta 443:235-244

35. Magonov SN, Yerina NA (2003) High-temperature atomic force microscopy of normal alkane $\mathrm{C} 60 \mathrm{H} 122$ films on graphite. Langmuir 36:5637 